\title{
Larvicidal and Repellent Potential of Chenopodium ambrosioides Linn Essential Oil against Anopheles gambiae Giles (Diptera: Culicidae)
}

\author{
Jude D. Bigoga ${ }^{1,2}$, Petola A. Saahkem ${ }^{1,2}$, Sali A. Ndindeng ${ }^{3}$, Judith L. Ngondi ${ }^{1}$, Maximilienne \\ Nyegue $^{1}$, Julius E. Oben ${ }^{1}$, and Rose G.F. Leke ${ }^{2,4}$. \\ ${ }^{1}$ Department of Biochemistry, University of Yaounde I, Cameroon \\ ${ }^{2}$ The Biotechnology Center University of Yaounde I, P.O Box 3851- Messa Yaounde, Cameroon \\ ${ }^{3}$ Institute for Agricultural Research and Development (IRAD) Nkolbisson, BP 2067 Yaounde, Cameroon \\ ${ }^{4}$ Faculty of Medicine and Biomedical Sciences, University of Yaounde 1, P.O Box 3851 - Messa Yaounde, Cameroon
}

\begin{abstract}
Larvicidal and repellent effect of the essential oil from the seeds and leaves of Chenopodium ambrosioides Linn were evaluated against the larvae and adults of Anopheles gambiae s.s. mosquitoes at concentrations of 0, 50, 75, $100,200,300$ and $400 \mathrm{ppm}$. Total mortality of larvae occurred at 200ppm and 300ppm for the essential oils from seeds and leaves respectively. Alpha-terpinene $(73.55 \%$ for the seeds; $40.69 \%$ for the leaves) and para-cymene $(20.05 \%$ for the seeds; $45.44 \%$ for the leaves) are the principal constituents. There was a $100 \%$ repellent effect on adult mosquitoes at $200 \mathrm{ppm}$, with protection time of at least four hours for both seed and leaf essential oils. The findings indicated that $C$. ambrosioides Linn possess mosquito larvicidal and repellent potentials that might be further exploited in combating malaria through anti-vector intervention.
\end{abstract}

Keywords: Malaria, Chenopodium ambrosioides, essential oil, Anopheles gambiae s.s., vector control.

\section{INTRODUCTION}

Vector borne diseases have continued to jeopardize human life worldwide. The most fatal, malaria kills more than a million persons annually and mostly sub-Saharan African children less than five years old. The overwhelming burden in sub-Saharan Africa is largely due to the presence of very efficient mosquito vectors of Plasmodium falciparum, the deadliest form of the malaria parasite. Despite considerable effort implored by control programs to curb the disease burden, it still remains a major public health problem in many endemic countries including Cameroon. According to the world health organization, vector control using insecticides is so far the most efficient means to fight against malaria, which is now being widely exploited in the treatment of bed nets and for indoor residual spraying (IRS) [1,2]. Nonetheless, the progressive development and spread of resistance to the major classes of insecticides in malaria vector populations, especially Anopheles gambiae complex is a huge challenge, which if not well managed is likely to directly and seriously affect the reemergence of malaria in areas where earlier control measures proved effective. Therefore, the need to develop new insecticides and alternative control measures is imperative. One of the recent focuses is to

*Address correspondence to this author at the Department of Biochemistry, University of Yaounde I, Cameroon; Tel: +23722237429;

Fax:+23722237429; E-mail: jbigoga@gmail.com control disease vectors using natural plant products that are effective against the target vector species. Natural plant products could serve as plausible alternatives to synthetic chemical insecticides as they would be environmentally safe, easily biodegradable, cost effective, and user friendly [3]; Although several studies have reported the larvicidal and repellence effects of essential oils from various botanicals against different mosquito species [4-10] for now the use for disease vector control is still very low [10].

Chenopodium ambrosioides Linn commonly known as worm seed is an indigenous perennial plant that is widely distributed throughout Cameroon $[11,12]$. The seeds of this plant are used as traditional insecticide to preserve post harvest grains such as maize (zea mays) and beans (Phaseolus Sp.) from weevil attack. Medicinal properties of this plant have also been reported; extracts are used against intestinal parasites, nervous infections, cough, pulmonary obstruction, typhoid, influenza, skin and kidney infection, anti- inflammatory as a carminative and emmenagogue $[13,14]$. The plant has also been shown to exhibit antipyretic, antifungal, antiviral, antibacterial, sedative, analgesic, antioxidant and insecticidal activities [12, 15-20]. Although C. ambrosioides essential oil has been previously reported to induce mortality in the larvae of mosquito species [21], the major constitutent of the plant, the terpenes (especially alpha terpinene and para-cymene), is highly variable depending on the geo- 
graphic location, climate and period of harvesting, which could lead to differential larvicidal effects in various parts of the world [22]. However, there are no reports yet on the larvicidal and repellent properties of this plant against $A$. gambiae s.s. This study therefore highlights on the larvicidal and repellent potential of the essential oils of the seeds and leaves of C. ambrosioides on A.gambiae s.s. larvae and adults as a means of contributing to malaria control through anti-vector intervention.

\section{MATERIALS AND METHODS}

\subsection{Plant Material and Production of Essential Oil}

Whole Chenopodium ambrosioides plants were harvested from Jakiri sub-division in the Northwest Region of Cameroon and transported to the laboratory for vector biology and control at the Biotechnology Center, University of Yaounde I. The seeds and leaves of the freshly harvested plants were separated and dried under shade by spreading on a clean and well-ventilated surface for one week. The plant parts were separately weighed and essential oils extracted by hydrodistillation using a Clevenger type apparatus. The oils were passed through cotton wool containing anhydrous sodium sulphate to remove all moisture and put in light insensitive glass bottles. The oil fractions were weighed and the yield calculated with respect to the weight of the dried plant part prior to extraction and stored at $4{ }^{\circ} \mathrm{C}$ until use. . The oils were brought to room temperature prior to the larvicidal and repellence testing.

2.2. Determination of the Chemical Composition of Essential oils by Gas Chromatography (GC) and Gas Chromatography-mass Spectrometry (GC-MS)

Analysis by GC was done using a Varian-CP 3380 single channel gas chromatograph, equipped with nonpolar HP-5 capillary column $(30 \mathrm{~m} \times 0.32 \mathrm{~mm} \times 0.25 \mu \mathrm{m})$. The oven temperature was programmed from 50 to $200{ }^{\circ} \mathrm{C}$ with a gradient of $5^{\circ} \mathrm{C} /$ minute. Nitrogen at $1 \mathrm{ml} / \mathrm{min}$ was used as the carrier gas. The sample, $1 \mu 1$ of the oil solution in hexane was injected in a split mode and the split ratio was 1:100. The injector and detector (FID) temperatures were operated at $200^{\circ} \mathrm{C}$..The Star Chromatography Work Station (STARWS, version 6.2) was used to control the system. Quantitative analysis was done by integrating the surface area of the peaks and the results expressed as relative percentages.

The GC/MS analysis was performed on a HEWLETTPACKARD 5970 system. The gas chromatograph was equipped with a HP-5 column $(30 \mathrm{~m} \times 0.25 \mathrm{~mm} \times 0.25 \mu \mathrm{m})$ and coupled with the quadrupole mass analyser (QMS) and detector at $70 \mathrm{eV}$. The oven temperature was raised from 70 to $200{ }^{\circ} \mathrm{C}$ at the rate of $10^{\circ} \mathrm{C} /$ minute. The injector port was isothermally held at $220^{\circ} \mathrm{C}$. Helium at $0.6 \mathrm{ml} / \mathrm{min}$ was used as carrier gas. The sample, $0.1 \mu \mathrm{l}$ of essential oil diluted to $10 \%$ with hexane was injected into the GC/MS apparatus in a split mode (split ratio 1:100). Identification of the constituents was confirmed based on the mass spectra and retention indices of authentic samples of the compound, and then comparing the Kovats indices to that in literature [23].

\subsection{Larval Collection and Rearing}

Anopheles gambiae s.s. larvae were collected from breeding sources around Yaounde by dipping. The larvae were sorted according to whether they were in their first, second, third or fourth instar in individual rearing bowls containing clean distilled water and covered with netting material. The larvae were fed with finely ground dog biscuit until the third and fourth instars were obtained for larvicidal bioassays or until the adults emerged for the repellence bioassays. Emerging adults were maintained on $10 \%$ sugar solution in adult cages.

\subsection{Larvicidal Bioassay}

Larvicidal bioassay was performed according to the standard world health organization (WHO) larval susceptibility test procedure with slight modification [21, 24]. Only third and fourth instar larvae were used for the bioassay. A stock solution made up of a 1:1 dilution of each essential oil fraction in $95 \%$ ethanol was prepared. From this, appropriate dilutions were prepared at 400,300, 200, 100, 75, 50 and 25 parts per million (ppm) with distilled water in individual white paper cups to final working concentrations and a final volume of $100 \mathrm{ml}$ each. Ten replicates were carried out for each test concentration. Using a Pasteur pipette, ten larvae were carefully transferred to each cup and allowed to stand at room temperature for one hour. Thereafter the larvae were transferred into clean cups containing distilled water only. No food was provided during the treatment. Larval mortality rates were recorded at 1 minute intervals for 5 minutes, then 10 minutes intervals for 60 minutes, and then at 24 hours. Larvae were considered dead if they failed to exhibit the characteristic dicing reaction when the water was perturbed. The mean mortality number was recorded. Two replicate controls were assayed simultaneously with $90 \mathrm{ml}$ distilled water and $10 \mathrm{ml}$ of $95 \%$ ethanol.

\subsection{Molecular Identification of Anopheles Gambiae Spe- cies}

Genomic DNA was extracted from randomly selected mosquito samples as described by Collins et al, (1987). The DNA was re-suspended in $25 \mu 1$ sterile TE-buffer $(10 \mathrm{mM}$ Tris- $\mathrm{HCl} \mathrm{pH} 8.1,1 \mathrm{mM}$ EDTA) and used to identify the members of the A. gambiae complex by the standard ribosomal DNA polymerase chain reaction according to Scott et al [25], including species-specific primers for A. gambiae, A. arabiensis, A. melas, A. quadriannulatus. Identification of the M/S molecular forms of $A$. gambiae s.s. was performed using the Restriction fragment length polymorphism (RFLP) PCR analysis of the X-linked ribosomal DNA as described previously [26]

\subsection{Repellence Evaluation}

The repellent potential of C. Ambrosioides seed and leaf essential oils were evaluated in two ways, namely, the animal test and the cage test. The essential oils were formulated as $30 \%$ lotions in absolute ethanol together with vanillin, propylene glycol and polyethylene glycol as additives and three concentrations of 50,100 and 200ppm prepared. For comparison with standard repellents, a commercial insect 
repellent lotion, "Ultrathon", containing 30\% diethyl-mtoluamide - DEET was used alongside a second control consisting of the diluents only ( $95 \%$ ethanol).

\subsubsection{The Animal Test}

A total of 22 guinea pigs, 10 for each essential oil fraction and 2 controls were used for this assay. The animals were shaved on the ventral side of the abdomen $(3 \mathrm{~cm} \mathrm{x}$ $10 \mathrm{~cm})$ to expose the skin and immobilised by tying the fore and hind limbs together. Beginning with the lowest concentration $(50 \mathrm{ppm}) 0.1 \mathrm{ml}$ essential oil fraction was applied on the shaved area of all ten animals. The treated portion was brought in contact with three days old blood starved female adult mosquitoes through the netted surface of mosquito cages $\left(196 \mathrm{~cm}^{2}\right)$, each containing ten mosquitoes and allowed to stand for 15 minutes, after which the number of blood fed mosquitoes was recorded. The repellence test continued until there were at least two blood fed mosquitoes. However, if there were no blood fed mosquitoes after three hours, the test was discontinued. This was repeated for the increasing concentrations at 100 and $200 \mathrm{ppm}$ respectively. Thus, each concentration was replicated 10 times giving a total of 100 mosquitoes per concentration. The tests were carried out under controlled laboratory conditions of $28+2^{\circ} \mathrm{C}$ and $80 \pm 2 \%$ relative humidity. Two control experiments were assayed simultaneously. Accordingly, $0.1 \mathrm{ml} / 196 \mathrm{~cm}^{2}$ of the commercial insect repellent cream, "Ultrathon", containing $30 \%$ diethyl-m-toluamide - DEET, was applied to the shaved ventral surface of one control animal, while $0.1 \mathrm{ml} / 196 \mathrm{~cm}^{2}$ of $95 \%$ ethanol only was applied on the second animal. The proportion of blood fed mosquitoes in the test and controls was recorded to estimate the percentage of protection.

\subsubsection{The Cage Test}

The test was performed under controlled laboratory temperature $\left(27+2^{\circ} \mathrm{C}\right)$ and relative humididty $(80+2 \%)$. One millilitre of the 50, 100 and 200ppm essential oil formulation per oil fraction was applied to the inner surface of a $604 \mathrm{~cm}^{2}$ cage linked to another cage (untreated) by a $196 \mathrm{~cm}^{2}$ white card board tunnel. Similarly, $1 \mathrm{ml} / 604 \mathrm{~cm}^{2}$ of a commercial insect repellent cream, "Ultrathon", containing 30\% diethylm-toluamide - DEET was applied to the inner walls of the control cage. The treated surfaces were air dried for 30 minutes and a total of one hundred 2-5 days old female An. gambiae introduced into each treated cage using mouth aspirators. The behaviour of the mosquitoes was observed every
30 minutes and the protection time measured as the time elapsed between the introduction of the mosquitoes into the treated cage and the time when mosquitoes having escaped into the untreated cage began returning into the treated cage. If no mosquitoes returned into the treated cage after four hours, the test was discontinued and the protection time simply recorded as 4hours. Each test concentration was replicated twice. Fig. (1) shows the set up for the cage test as designed by the authors for the first time and named the "Bigoga Model".

\subsection{Statistical Analysis}

Probit Analysis software WINDL 32 with $95 \%$ confidence interval was used to calculate the $\mathrm{LC}_{10}, \mathrm{LC}_{50}$ and $\mathrm{LC}_{90}$.

\section{RESULTS AND DISCUSSION}

\subsection{Yield and Chemical Composition of the Essential Oils}

The yield of the essential oil of the seeds was $2.43 \%$ while that for the leaves was $1 \%$. $\alpha$ terpinene and $\rho$-cymene were the most abundant components (Tables 1 and 2), both soluble in ethyl alcohol. The essential oil of the seeds contained $73.55 \% \alpha$ terpinene and $20.05 \% \rho$-cymene with one unidentified compound (4.23\%). The essential oil of the leaves contained $45.44 \% \rho$-cymene and $40.69 \% \alpha$ - terpinene with two unidentified compounds $(1.28 \%$ and $2.89 \%)$. The compounds obtained from this study differed from those obtained in earlier studies on the same plant from different geo-ecological locations around the world. Some compounds such as ascaridol previously reported to be the principal constituent of this plant was absent $[9,16]$. Such variation might be due to differences in ecological factors such as soil water content, nutrient amounts and quality, luminosity, temperature and relative humidity; all of which would influence the metabolism of the essential oils [27].

\subsection{Larvicidal Properties of the Essential Oil Fractions}

The two essential oils showed direct proportionality between the percentage mortality and the essential oil concentration. The minimum concentration required to obtain $100 \%$ larval mortality was $200 \mathrm{ppm}$ for the seeds and $300 \mathrm{ppm}$ for the leaves essential oils. This suggests the essential oil of the seeds of $C$ ambrosioides could have better larvicidal activity compared to that of the leaves; though the difference was not

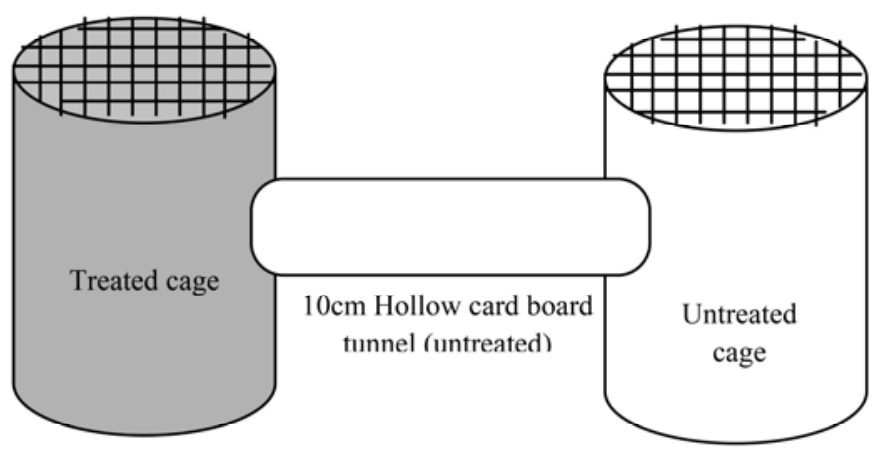

Fig. (1). Set up for repellence evaluation using the cage assay method (Bigoga model). 
Table 1. Chemical Composition of the Essential Oil of the Seeds and Leaves of C. ambrosioides

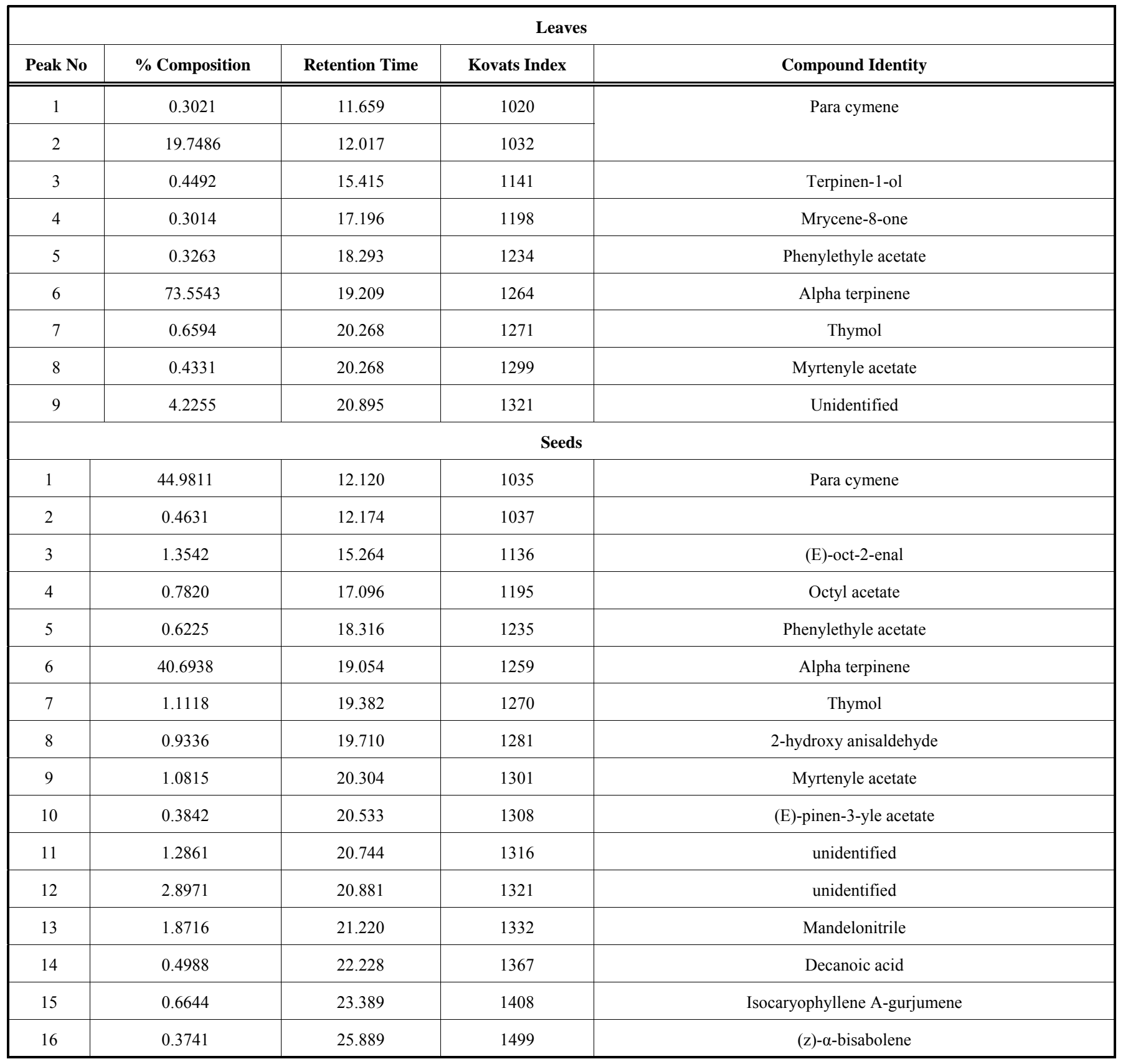

significant (Fig. 2). However, the essential oil concentration needed to kill $50 \%\left(\mathrm{LC}_{50}\right)$ of the larvae in the larvicidal bioassay was $75 \pm 3.19 \mathrm{ppm}$ for the seeds and $77 \pm 4.24 \mathrm{ppm}$ for the leaves. This observation is probably due to slight differences in the percentage composition of the constituent compounds in the two fractions, especially $\alpha$ terpinene and $\rho$ cymene (Table 1). The larvicidal activity of these essential oils was also shown by the $\mathrm{LC}_{10}, \mathrm{LC}_{50}$ and $\mathrm{LC}_{90}$ values (Table 2) with similar lethal trends for both the leaf and seed fractions. This compelling anti-larval activity is most likely due to the dominant essential oil components, $\alpha$-terpinene and $\rho$-cymene, both previously reported to exhibit important larvicidal activities and inhibitory effects on other mosquito species $[28,29]$. The high mortality of this species at very low concentrations of the essential oils is indicative that if properly exploited, it could serve as a useful biological alternative to synthetic chemical larvicides for malaria control. Also it would have the advantage of being environmentally harmless, easily biodegradable and cost effective as the plant; C. ambrosioides can be easily cultivated. Molecular identification of collected and used specimens revealed that only A. gambiae s.s. (M form) was included in this study.

\subsection{Repellence Properties}

Figs. (3 and 4) depict the repellent effects of C. Ambrosioides using the cage and animal models respectively. In the cage model, despite allowing for at least three hour exposure, 
Table 2. $\quad \mathrm{LC}_{90}, \mathrm{LC}_{50}$ and $\mathrm{LC}_{10}$ for Larvicidal Bioassay of An. gambiae s.s. Larvae

\begin{tabular}{|c|c|c|}
\hline LC & Dose for Seeds Essential Oil (ppm) [95\%CI] & Dose for Leaves Essential Oil (ppm) [95\%CI] \\
\hline \hline $\mathrm{LC}_{90}$ & $100[92.35-106.11]$ & $118.69[108.98-133.38]$ \\
\hline $\mathrm{LC}_{50}$ & $75[68.25-79.63]$ & $77[72.76-81.20]$ \\
\hline $\mathrm{LC}_{10}$ & $50[47.61-55.60]$ & $50[44.42-54.06]$ \\
\hline
\end{tabular}

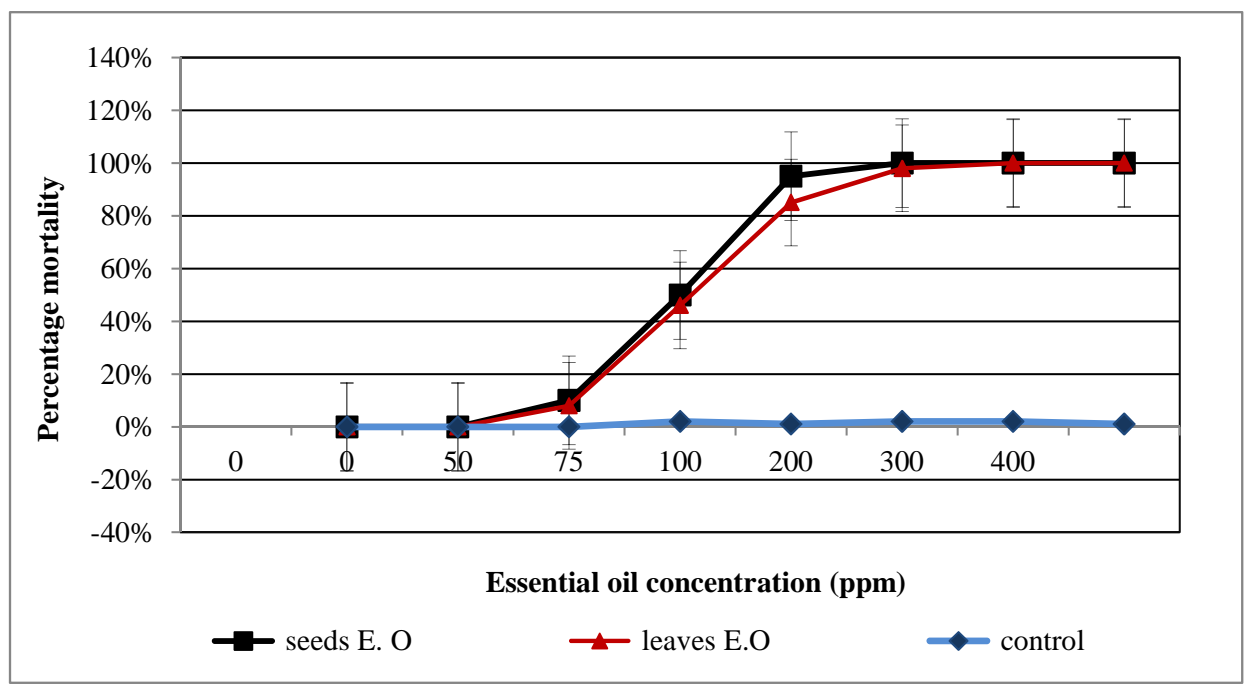

Fig. (2). Larvicidal effects of the leaf and seed essential oil fractions on Anopheles gambiae.

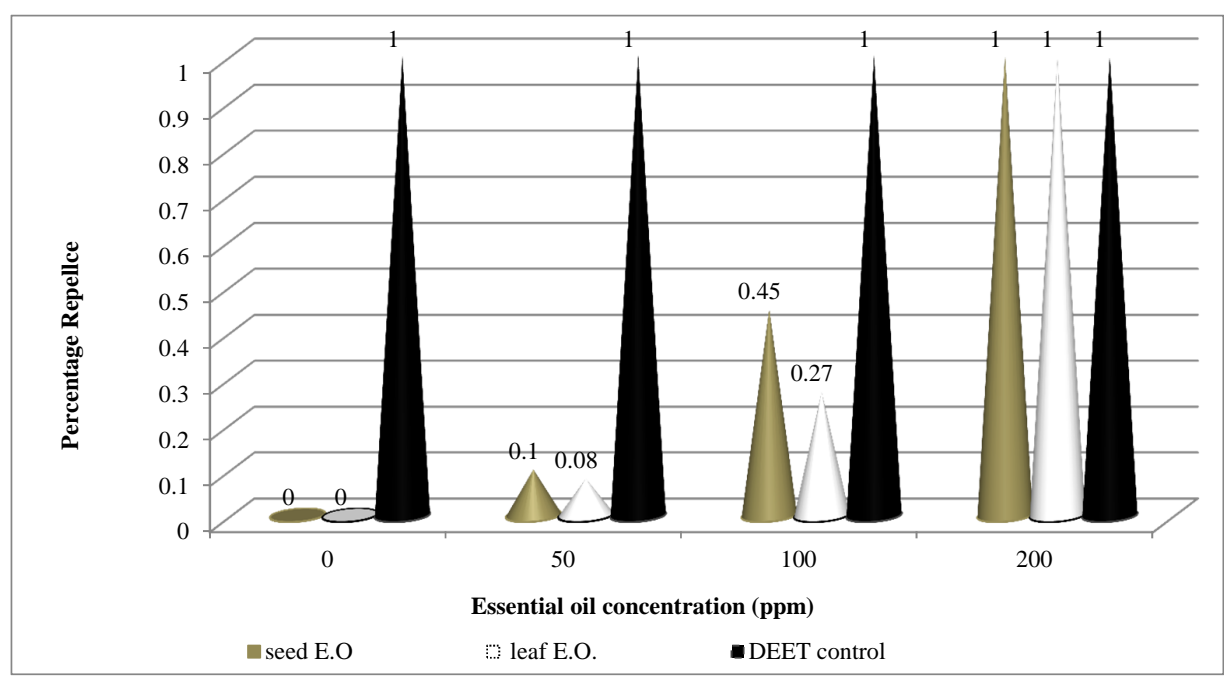

Fig. (3). Repellence effects of the leaf and seed essential oil fractions on adult Anopheles gambiae s.s. mosquitoes using the cage model.

all test as well as control (DEET) mosquitoes escaped from the treated cages $(200 \mathrm{ppm})$ into the untreated cages within 10 minutes of exposure and did not return to the treated cages; an indication that the oil fractions have a fast mode of action on mosquitoes. However, at concentrations below $200 \mathrm{ppm}$, the repellence rate was generally below 50\%. With regards to the animal test, while no mosquito successfully fed on the test animals at 200ppm of the essential oil concentration, the feeding rate in the control with the commercial insect repellent, DEET, was $0 \%$ and about $27 \%$ with ethyl alcohol. The efficacy of DEET in providing protection against a wide variety of mosquito species has been reported previously [30, 31]. Although an effective repellent against mosquitoes, there are concerns associated with DEET use in humans [32]. The fact that C. Ambrosioides has for long been used traditionally for medicinal purpose and in the protection of post harvest grains is suggestive of its safety to humans at very low concentrations [15-18]. The result in this study is an indication that the essential oil of C. ambrosioides has potential repellent action against $A$. gambiae s.s, the major vector species for Plasmodium falciparum in Africa. C. ambrosioides essential oil therefore may be considered a potentially effective repellent and a likely natural alternative to synthetic repellents if properly exploited. 


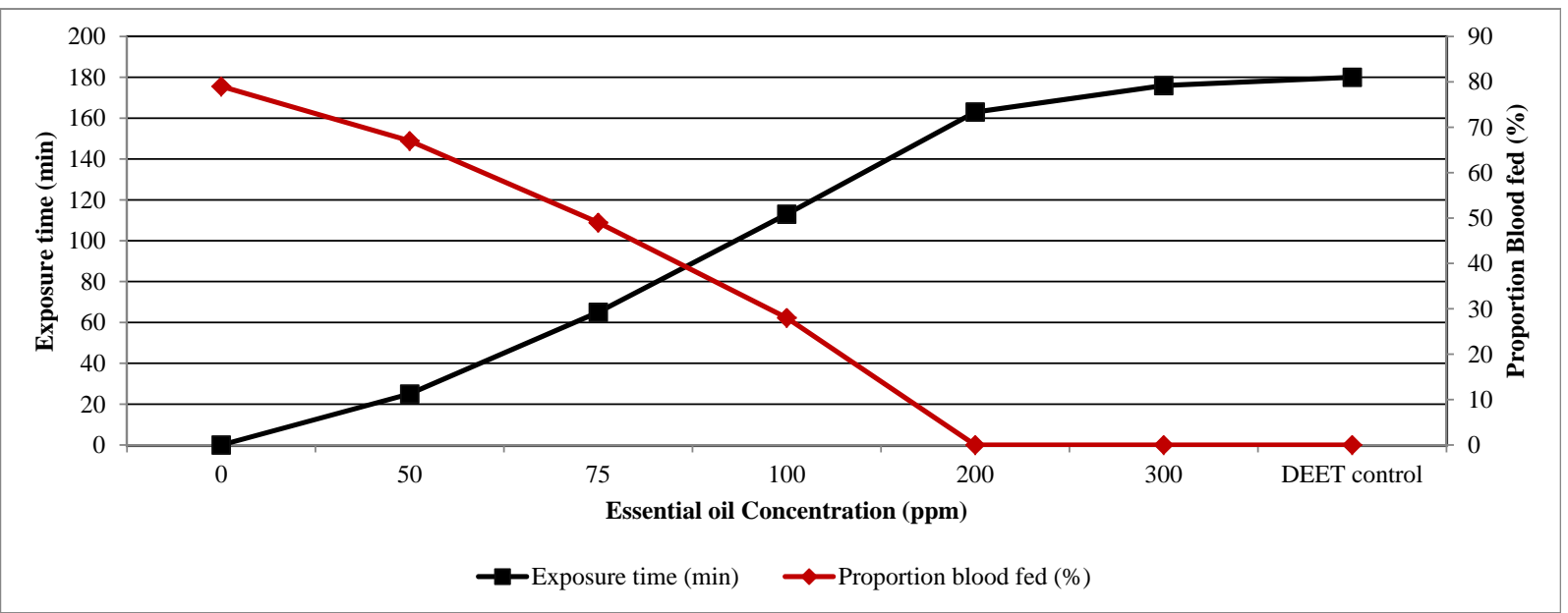

Fig. (4). Proportion of blood feeding female Anopheles gambiae at various concentration of the essential oil of $C$. ambrosioides using the animal model.

Overall, the essential oil of C. ambrosioides possesses considerable larvicidal and repellent efficiency against the larvae and adults of Anopheles gambiae s.s mosquitoes respectively. Though promising, in order to use C. ambrosioides as an effective biological tool for combating malaria through anti-vector intervention, the larvicidal and repellence activities need to be investigated further; meanwhile an innovation on the delivering technology is needed. It would also be important to cautiously evaluate their selective toxicity on mosquito larvae in the presence of other aquatic entomofauna under natural field conditions.

\section{CONFLICT OF INTEREST}

The authors confirm that this article content has no conflicts of interest.

\section{ACKNOWLEDGEMENTS}

The authors are thankful to the laboratory of Phytobiochemistry, Department of Biochemistry, University of Yaounde I for assistance in the essential oil extraction and the Laboratory of Biomolecular chemistry, Université de Montpellier Cedex 5, France, for analysis of the essential oil composition. We were able to realize this thanks to the Government of Cameroon through the Ministry of Higher Education and the University of Yaounde I financial research support.

\section{REFERENCES}

[1] Yakob L, Dunning R, Yan G. Indoor residual spray and insecticidetreated bednets for malaria control: theoretical synergisms and antagonisms. J Roy Soc Inter 2011; 8(59): 799-806.

[2] Bigoga JD, Ndangoh DN, Awono-Ambene HP, Patchoke S, Fondjo E, Leke RGF. Pyrethroid resistance in Anopheles gambiae from the rubber cultivated area of Niete, South Region of Cameroon. Acta Trop 2012; 124(3): 210-14.

[3] Redwane A, Lazrek HB, Bouallam S, Markouk M, Amarouch H, Jana M. Larvicidal activity of extracts from Querus lusitania var. infectoria galls (oliv). J Ethnophamacol 2002; 79: 261-3.

[4] Duangkamon S, Soonwera M, Waltanachanobon S, Poungjai S. Evaluation of herbal essential oil as repellents against Aedes aegypti $(L)$ and Anopheles dirus Peyton and Harrion. Asian Pacific J Trop Biomed 2011; S124-8.
[5] Amer A, Mehlhorn H. Persistency of larvicidal effects of plant oil extracts under different storage conditions. Parasitol Res 2006; 99 : 473-7

[6] Morais SM, Cavalcanti ESB, Bertini LM, Oliveria CLL, Rodrigues JRB,Cardoso JHL. Larvicidal activity of essential oils from Brazilian Croton species against Aedes aegypti L. J Am Mosq Control Assoc 2006; 22: 161-4

[7] Jantan I, Yalvema MF, Ahmad NW, Jamal JA. Insecticidal activities of the leaf oils of eight Cinnamomum species against Aedes aegypti and Aedes albopictus. Pharm Biol 2005; 43: 526-32.

[8] Tare V, Deshpande S, Sharma RN. Susceptibility of two different strains of Aedes aegypti (Diptera: Culicidae) to plant oils. J Econ Entomol 2004; 97: 1734-6.

[9] Pitasawat B, Choochote W, Kanjanapothi D, Panthong A, Jitpakdi A, Chaithong U. Screening for larvicidal activity of ten Carminative plants. Southeast Asia J Trop Med Public Health 1998; 29: 660-2.

[10] Raghavendra K, Barik TK, Reddy BP, Sharma P, Dash AP. Malaria vector control: from past to future. Parasitol Res 2011; 108(4): 757-79.

[11] Burkill H. Useful plants of west tropical Africa, $2^{\text {nd }}$ ed. Richmond Surrey, London: Kew Publishing 1985.

[12] Chekem MSG, Lunga PK, Tamokou JD, et al. Antifungal properties of Chenopodium ambrosioides essential oil against Candida species. Pharmaceuticals 2010; 3: 2900-9.

[13] Yadav N, Vasudeva N, Singh S, Sharma S. Medicinal properties of the genus Chenopodium Linn. Nat Prod Radiance 2007; 6 (2): $131-4$.

[14] Ruffa M, Ferraro G, Wagner M, Calcagno M, Campos R, Cavallaro L. Cytotoxic effect of Argentine medicinal plant on human hepatocellular carcinoma cell line. J Ethnopharmacol 2002; 79: 335-9.

[15] Hegazy A, Farrag H. Allelopathic potential of Chenopodium ambrosioides on germination and seedling growth of some cultivated and weed plants. Glob J Biotechnol Biochem 2007; 2(1): 1-9.

[16] Gadano A, Guni A, Lopez P, Ferraro G, Carballo M. In vitro genotoxic evaluation of the medicinal plant Chenopodium ambrosioides Linn. J Ethnopharmacol 2002; 81: 1-16.

[17] Hallal SB, Markouka M, Bekkouche K, et al. Evaluation of the analgesic and antipyretic activities of Chenopodium ambrosioides L. Asian J Exp Biol Sci 2010; 1 (1): 189-92.

[18] Jardim C, Jham G, Dhingra O, Freire M. Composition and antifungal activity of the essential oil of the Brazilian Chenopodium ambrosioides L. Toxicol Appl Pharmacol 2008; 240(3): 337-47.

[19] Kumar R, Mishra A, Dubey N, Tripathi Y. Evaluation of Chenopodium ambrosioides oil as a potential source of antifungal, antiaflatoxigenic and antioxidant activity. Int J Food Microbiol 2007; 115: $159-64$.

[20] Tapondjou L, Adler C, Bouda H, Fontem D. Efficacy of powder and essential oil from Chenopodium ambrosioides leaves as postharvest grain protectants against six-stored product beetles. Stored Prod Res 2001; 38(4): 395-402. 
[21] Fekadu M, Mekuria T, Tesfaye B, Meshesha B, Gebre-Michael T. Evaluation on larvicidal effects of essential oils of some local plants against Anopheles arabiensis Patton and Aedes aegypti Linnaeus (Diptera, Culicidae) in Ethiopia. Afr J Biotechnol 2009; 8(17): 4183-8.

[22] Cavalli F, Tomi F, Bernardini F, Casanova J. Combined analysis of the essential oil of Chenopodium ambrosioides by GC, GC-MS and 13C-NMR spectroscopy: quantitative determination of ascaridole, a heat-sensitive compound. Phytochem Anal 2004; 15, 275-9.

[23] Adams R. Identification of essential oils by gas chromatography/quadrupole mass spectroscopy. Carol Stream, IL, USA: Allured Publishing Corp 2001.

[24] WHO. Instructions for determining the susceptibility or resistance of mosquito larvae to insecticides. WHO/VBC/81.807.Geneva WHO 1981.

[25] Scott JA, Brogdon WG, Collins FH. identification of single specimens of the Anopheles gambiae complex by the polymerase chain reaction. Am J Trop Med Hyg 1993; 49: 520-9.

[26] Favia G, Lanfrancotti A, Spanos L, Siden-kiamos I, Louis C. Molecular characterization of ribosomal DNA polymorphisms discriminating among chromosommal forms of Anopheles gambiae s.s. Insect Mol Biol 2000; 10: 19-23.
[27] Ngamo T, Noudjou W, Ngassoum M, et al. Investigation of both chemical composition and insecticidal activities of essential oils of Vepris heterophylla (Rutaceae) from two localities of Northern Cameroon towards Tribolium castaneum (herbst). Res J Biol Sci 2007; 2(1): 57-61.

[28] Sen-Sung C, Meng-Thong C, Kun-Hsien T, Wei-June C, ShangTzen C. Variations in insecticidal activity and chemical compositions of leaf essential oils from Cryptomeria japonica at different ages. Bioresour Technol 2009; 100: 465-70.

[29] Pitarokili D, Michaelakis A, Koliopoulos G, Giatropoulos A, Tzakou O. Chemical composition, larvicidal evaluation, and adult repellency of endemic Greek Thymus essential oils against the mosquito vector of West Nile virus. Parasitol Res 2011; 109(2): 425-30.

[30] Fradin MS, Day JF. Comparative efficacy of insect repellents against mosquito bites. New Eng J Med 2002; 347: 13-8.

[31] Roberts JR, Reigart JR. Does anything beat DEET? Pediatr Ann 2004; 33: 443-53.

[32] Briassoulis G, Narlioglou M, Hatzis T. Toxic encephalopathy associated with use of DEET insect repellents: a case analysis of its toxicity in children. Hum Exp Toxicol 2005; 20: 8-14.

(C) Bigoga et al.; Licensee Bentham Open.

This is an open access article licensed under the terms of the Creative Commons Attribution Non-Commercial License (http://creativecommons.org/ licenses/by-nc/3.0/), which permits unrestricted, non-commercial use, distribution and reproduction in any medium, provided the work is properly cited. 